\title{
Por um jornalismo latino-americano realista, literário e mágico: uma leitura das crônicas de Gabriel García Márquez
}

For a realistic, literary and magical Latin American journalism: a reading Gabriel García Márquez' chronicles

Florence Marie Dravet

Doutora em Ciências da Linguagem pela Sorbonne - Paris 3, professora do Mestrado em Comunicação da Universidade Católica de Brasília (UCB). Em 2011, fez pós-doutorado em

Comunicação no PPGCOM- UnB

Resumo: Este artigo busca mostrar que existe um jornalismo literário na América Latina com características singulares, devido a uma realidade propriamente latino-americana em que o realismo é também mágico. Mostraremos isso por meio de uma leitura das crônicas de Gabriel García Márquez.

Palavras chave: Jornalismo. Literatura. Realismo mágico. Mito. Gabriel García Márquez.

Abstract: The present article attempts to demonstrate that a literary journalism, with its own particular characteristics, exists in Latin America due to a particular Latin American reality, whose realism is also magic. We will depict it through a reading of Gabriel Garcia Marquez's chronicles.

Keywords: Journalism. Literature. Magical realism. Myth. Gabriel García Márquez. 


\section{Introdução}

Uma das qualidades imprescindíveis a um bom jornalista é seu domínio de linguagem. A língua pode ser senhora da comunicação, mas o comunicador é, sem dúvida, aquele que se torna senhor de sua língua. Em suma, para ser jornalista é necessário ser um pouco escritor. Também é necessário saber parar, olhar e escutar a realidade; e mais, como um escritor, ser capaz de ver além dos cânones das aparências e revelar algo ao leitor que ele, sozinho, não pode enxergar.

Se nem todos os jornalistas acreditam na importância da literatura em sua formação e em sua prática, houve no mundo vários jornalistas-escritores que superaram as expectativas da informação e souberam encantar seus leitores com relatos da realidade muito mais profundos e sensíveis porque eram exímios senhores de sua língua. No Brasil, segundo Gustavo de Castro:

\footnotetext{
O que fez Euclides da Cunha, em Os Sertóes, nos permite rever alguns limites que impomos aos acontecimentos, como forma de comunicar a experiência humana através das geraçôes ou dentro de uma mesma geração. Isto porque Cunha, assim como Graciliano Ramos e João do Rio, entre outros, foram vanguarda e romperam os limites canônicos estabelecidos. Ao romper esses limites tais autores nos disseram sem dizer que comunicação é literatura e vice-versa. Arte menor, factual, o jornalismo não pode querer se igualar à literatura; deve, ao contrário, aprender com ela assim como tem aprendido com a história, a religião, os mitos e a filosofia. Aí está o seu valor de arte e de sabedoria. Quando o jornalismo aproxima-se da literatura, camuflando-se nela, não faz outra coisa senão mostrar todo o seu valor de arte híbrida, mestiça e complexa (CASTRO, 2010, p. 34-35).
}

No prefácio ao volume $\mathrm{V}$ da reedição pela Record de toda a obra jornalística de Gabriel García Márquez, em 2006, Léo Schlafman mostra, com ênfase e admiração, a fidelidade do consagrado escritor de romances como "Cem anos de solidão e "Crônicas de uma morte anunciada", à imprensa cotidiana e afirma que García Márquez tratava seus textos jornalísticos com o mesmo cuidado que dispensava à sua literatura: horas de trabalho por página, reescritura e ajustes, palavra a palavra, até que considerasse o artigo ou a crônica prontos. É que na verdade, como dizia outro jornalista escritor latino-americano, Tomás Eloy Martínez, “jornalismo e literatura se confundem”. Indo além da noção norte-americana de new journalism e até mesmo da ideia de jornalismo literário, os dois escritores têm o jornalismo como uma modalidade da literatura. Para eles, o jornalismo é genuinamente literário.

Mas o que faz Gabriel García Márquez em sua prática jornalística para alcançar simultaneamente tamanho grau de literariedade e realismo? O procedimento pode ser sintetizado da seguinte maneira: ele eleva o fato ao mito. 
Isso significa dizer que o que seria notícia, fato, envolvendo pessoas, tempos e lugares, nos textos do escritor, torna-se mito. O tempo adquire o valor de um mito, os lugares adquirem o valor de mitos, as pessoas adquirem o valor de mitos, os acontecimentos tornam-se míticos. Com a literariedade atuando no texto, tudo é elevado ao nível universal do mito.

Mostraremos aqui, por meio da leitura de algumas crônicas, que a elevação do texto jornalístico ao nível do mito é um procedimento que atua de três formas: 1) transformando a realidade de um fato singular em uma realidade de caráter universal; 2) colocando o leitor diante da questão da realidade e dos limites do real; 3) permitindo o acesso do leitor a universos novos de possibilidades tanto no nível da vivência, como no nível da crença. Dessas três formas é possível fazer um jornalismo que não apenas trate de informação, mas sim de formação e conhecimento.

O mito é algo capaz de agir de modo transformador sobre a realidade humana, impregnando as linguagens, o senso comum, a sensibilidade, as narrativas. Segundo Regis de Moraes (1988), o mito é:

\footnotetext{
O sagrado [que] busca devolver o universo cósmico, reunificado por uma inteligibilidade não racionalista, mas fideísta. Uma nova intuição mágica [que] reinventa a realidade para grande quantidade de seres humanos que, ao contrário de passarem a enxergar outro mundo, enxergam o mesmo mundo de uma forma diferente - a partir de um ângulo novo (MORAES, 1988, p. 24).
}

Em primeiro lugar, isso é importante porque com a elevação ao mito, o fato deixa de ser um acontecimento singular (realidade acontecida) para se tornar universal (o real por trás da realidade), o que aumenta o poder comunicativo da notícia.

\section{Transformando o fato em camadas de realidade}

Tomemos, por exemplo, a crônica escrita por García Márquez no dia da morte de Ernest Hemingway, em 1961. Só a primeira frase do texto basta para entender: "Desta vez parece ser verdade: Ernest Hemingway morreu." (GARCÍA MÁRQUEZ, 2006, p. 17). Aqui, não importa quando, como, nem onde, diante da imponência do personagem que morre sem morrer verdadeiramente (apenas parece): Ernest Hemingway. O homem-escritor ganha uma dimensão quase sobrenatural. Depois, o cronista continua: "A notícia comoveu, em lugares opostos e distantes do mundo, os seus garçons de café, seus guias de caçadas, seus aprendizes de toureiro, seus motoristas de táxi, uns tantos pugilistas decadentes e alguns pistoleiros aposentados.” (2006, p. 17). Aqui, 
o escritor brinca com a realidade e a ficção, os personagens dos romances de Hemingway se confundem com as pessoas que ele, talvez, tenha conhecido de verdade em suas andanças aventureiras pelo mundo (real? ficcional?). O final da crônica também servirá de exemplo de como se transforma o personagem central de um fato noticioso em mito:

\footnotetext{
Essa é talvez a dimensão mais exata de Hemingway. Provavelmente não é o fim de alguém, mas o princípio de ninguém na história da literatura universal. Mas é o legado natural de um esplêndido exemplar humano, de um trabalhador bom e singularmente honrado, que talvez mereça algo mais do que um lugar na glória internacional (2006, p. 19).
}

Ora, um lugar na glória internacional não era o que mais se esperava para um escritor do renome de Hemingway? Não, García Márquez consegue fazer mais, consegue transformar o escritor realista em um ser que não é ninguém, que pode ser todos nós, um universal, eu, você, um homem, natural. Esse é o verdadeiro poder do mito: saber se os deuses existem de fato. Onde nasceram e morreram é o que menos importa; o que interessa é que estáo eternamente vivos em algum lugar de incerteza, em um tempo a-histórico, e que todos nós somos um pouco deuses. Este é o movimento: do universal ao singular, do singular ao universal, incessantemente.

Outro exemplo, da crônica O fantasma do Prêmio Nobel: "Todos os anos, por estes dias, um fantasma inquieta os grandes escritores: o Prêmio Nobel de Literatura" (2006, p. 39) Com a primeira frase, já está criada a atmosfera: medo, inquietude, desconhecido, ansiedade entre os grandes escritores. O Prêmio Nobel - desconhecido entre os menos informados em matéria de prêmios - encontra-se desde já elevado ao grau de mito, um fantasma que não pode mais ser ignorado. Basta uma frase e a transformaçáo acontece.

Outro exemplo pode ser encontrado ainda em $A$ mulher que escreveu um dicionário (trata-se de María Moliner, única autora do Dicionário de uso do espanhol, mais de três mil páginas e três quilos) que, já perto do final, diz:

Agradavam-lhe as notícias de que seu dicionário vendera mais de dez mil exemplares, em duas ediçóes, que cumpria o projeto que ela se impusera e que alguns acadêmicos da língua consultavam em público sem se ruborizar. Às vezes, vinha um jornalista ou outro. A um deles, que lhe perguntou por que não respondia às numerosas cartas que recebia, respondeu com mais frescor do que o de suas flores: - Porque sou preguiçosa (2006, p. 113-114). 
A crônica mais parece um conto em que a personagem central é uma fada entre as flores. E os exemplos são infinitos; podem ser encontrados em cada uma das crônicas e têm, de fato, um efeito poderoso sobre o que se pode conseguir no nível da comunicação. A literatura consegue elevar aquilo que é factual, singular, aquilo que aconteceu aqui e agora (os cinco W do lead) a um nível de universalidade capaz de potencializar os efeitos comunicativos de divulgação, propagação, difusão, impacto, repercussão da informação. Com o universal, a literatura extirpa o jornalismo da pequenez do factual e da informação pura e simples. Sim, porque não acreditamos na ilusão de que as pessoas só querem se informar. Não. Isso é muito pouco. O que elas querem é muito maior: elas querem saber. E o saber é mais que a informação. O saber contém também as delicadas dimensóes da sensibilidade, da emoção e da sabedoria que não estão presentes na informação em sentido estrito.

\section{O leitor diante dos limites do real}

É necessário elevar o fato ao mito. Isso significa também que, o tempo todo, as pessoas, os leitores são colocados diante da difícil questão do real. A todo momento, o leitor é convidado a pensar: o que é real? O que não é? Com a literatura, parece que a ficção é real. Isso porque uma coisa é a realidade acontecida (mais uma vez, o fato noticioso) e outra coisa é o real que se apresenta por trás do fato e que só a literariedade pode fazer surgir, não como uma imposição (como o faz a ciência), mas como uma possibilidade.

Assim, embora nos tivessem ensinado que o jornalismo tinha que se ater à realidade dos fatos, o jornalismo de García Márquez faz mais que isso, porque é também um convite à reflexão sobre os difíceis limites entre realidade e ficção. García Márquez parece, então, se divertir com o provável sentimento de estranhamento, de incerteza, de desconcerto ou até desconforto, que podem causar seus textos - sentimentos estes, porém, que podem se tornar agradáveis aos espíritos abertos às infinitas possibilidades do real. Com efeito, o que permite a fruição do literário no jornalismo é a abertura às múltiplas possibilidades do real.

Escrevemos, em outros espaços, que o que é necessário entender é que a razão mítica - o mythos em contraponto ao logos - não é uma razão injuntiva, e sim propositiva. Não é uma razão que busca a comprovação através da argumentação lógica, e sim uma razão que oferece possibilidades para o pensamento, que possibilita àquele que dela participa um lugar no complexo de relaçóes que são tecidas a todo momento, entre todos os entes do sistema cósmico. Nesse sentido é uma razão aberta.

Enquanto uma razão logocêntrica busca lógicas predominantemente objetivas e igualmente compartilháveis, a razão mítica é aberta porque oferece múltiplas e infinitas possibilidades de sentidos que dependem da sensibilidade 
e da percepção subjetiva. O mito se dá a conhecer como uma proposta que vaga no espaço aberto, mas ele se realiza e adquire seu sentido quando atravessa o ser humano e se desdobra em possibilidades que aderem aos percursos meândricos de sua interioridade subjetiva. $\mathrm{O}$ mito, nesse sentido, é uma narrativa das incertezas.

Nas crônicas de García Márquez encontramos exemplos dessas incertezas informativas de alto valor poético em vários níveis: 1) No nível temporal (a resposta ao imprescindível 'quando?'): “Uma vez, sendo repórter em Bogotá, numa época irreal em que todo mundo tinha vinte anos (...)” (2006, p. 51); 2) $\mathrm{Na}$ descrição de alguns personagens (o não menos imprescindível 'quem?'): "Era uma jovem tão bela e sábia que não pretendia saber mais que podia, e era tão jovem que com o tempo acabou por ser mais nova que eu" (2006, p. 105); 3) Nas circunstâncias do fato: "O tempo estava perfeito e o avião parecia imóvel no céu, levando ao seu lado essa estrela solitária que sempre acompanha os bons avióes" (2006, p. 52); 4) Nas consequências do fato: "Nessas condiçóes indesejáveis compreendi por que a comida servida em pleno vôo é de uma natureza diferente da que se come em terra firme. É que também o frango - morto e assado - voa com medo (...)" (2006, p. 119);

E ainda na escolha dos temas: Gabriel García Márquez tem um gosto especial por abordar fenômenos ditos sobrenaturais em suas crônicas jornalísticas. Fenômenos estes que, diga-se de passagem, são tratados com muita naturalidade nas culturas latino-americanas - telepatia, presságios, mau augúrio, adivinhaçôes, apariçôes etc - mas que ele trata de maneira às vezes irônica, às vezes ambígua, às vezes natural.

Na crônica $A$ comissão de Babel, García Márquez conta sua experiência como membro de uma Comissão internacional de dezesseis pessoas de diferentes origens e nacionalidades, e de línguas diferentes, reunidas para estudar a Comunicação e a Informação no mundo contemporâneo, a pedido da UNESCO:

\footnotetext{
Para mim, que sou um caçador solitário de palavras, escrever um livro juntamente com outras quinze pessoas, e além disso tão diferentes, era uma aventura perturbadora. Resultou ser a mais surpreendente: nunca me aborreci tanto e nem me senti tão inútil; mas creio que nunca aprendi tanto em tão pouco tempo. No fim, só me ficou a amargura de não ter podido demonstrar que a telepatia, os presságios e os sonhos cifrados são meios de comunicação naturais que é necessário resgatar do obscurantismo científico (2006, p. 64).
}

Já na crônica Telepatia sem fio, o escritor expóe sua perplexidade diante de alguns fenômenos telepáticos inegáveis, mas fala, sobretudo, de sua perplexidade diante da descrença e da falta de informação dos pesquisadores e cientistas a esse respeito: 
Um notável neurologista francês, pesquisador em tempo integral, contou-me outra noite que descobrira uma função do cérebro humano que parece ser de grande importância. Só há um problema: não pode definir para que serve. Perguntei-lhe, com alguma esperança, se havia possibilidade de que fosse a função que regula os presságios, os sonhos premonitórios e a transmissão de pensamento. Sua única resposta foi um olhar de compaixão (2006, p. 67).

Na mesma perspectiva crítica, García Márquez escreve uma crônica chamada Fantasmas de estrada que se inicia assim:

Dois rapazes e duas moças que viajavam num Renault 5 deram carona a uma mulher vestida de branco que lhes fez sinais numa encruzilhada pouco depois da meia-noite. O tempo estava claro e os quatro jovens - como se comprovou depois à saciedade - estavam em seu perfeito juízo. A mulher viajou em silêncio vários quilômetros, sentada no meio do banco de trás, até um pouco antes da ponte de Quatre-Canaux. Então apontou para frente com o dedo indicador e gritou: - Cuidado, essa curva é perigosa - e desapareceu. [...] Quase toda a imprensa francesa comentou o caso nos dias seguintes, e numerosos parapsicólogos, ocultistas e repórteres metafísicos foram ao local da aparição para estudar suas circunstâncias [...] Mas ao cabo de poucos dias, tudo caiu no esquecimento e tanto a imprensa como os cientistas se refugiaram na análise de uma realidade mais fácil (2006, p. 237).

Finalmente, como exemplo do tratamento natural dado por vezes às questôes obscuras dos fenômenos paranormais e sobrenaturais, várias crônicas narram as experiências vividas pelo escritor no seio de sua própria família: "Enquanto conversávamos, chegou uma neta para nos contar que na noite anterior se desdobrara em duas: - Quando voltei do banheiro - me disse - me encontrei comigo mesma que ainda estava na cama" (2006, p. 130). E mais:

\footnotetext{
Minha vó materna foi o sábio mais lúcido que jamais conheci na ciência dos presságios. Era uma católica como as de antigamente, de maneira que repudiava como artifícios demoníacos tudo o que pretendesse ser adivinhação metódica do futuro. Assim foram os baralhos, as linhas da mão ou a evocação dos espíritos. Mas era mestra em seus presságios. Recordo-a na cozinha de nossa casa grande de Aracataca, vigiando os signos secretos dos pães perfumados que tirava do forno. Uma vez viu 09 escrito nos restos da farinha [...] (2006, p. 69).
} 
É aqui que uma razão aberta se torna atuante. Justamente porque é aqui que a razão ultrapassa as camadas da língua conhecida, estruturada, descrita e vulgarizada pelo uso da conversação e da prosa e que, submetida aos desafios e à tensão, é forçada a elevar-se aos domínios das novas possibilidades, da superação, da criação. Ao imaginar o mistério, o espírito humano supera as limitaçôes de sua própria linguagem e estende a esfera de seu pensamento e, consequentemente, de sua língua para o domínio das novas possibilidades. Ele se torna um criador, um dramaturgo, um demiurgo. Ele faz o impossível tornar-se possível.

\section{O jornalista-escritor como criador de mundos}

O terceiro significado contido no procedimento literário que consiste em "elevar o fato ao mito" está na capacidade do escritor de extirpar as pessoas do seu cotidiano conhecido e previsível, para mergulhá-las em novos mundos, universos descritos com tal maestria que a leitura mais se parece com uma viagem a outros tempos, outros lugares, outras realidades. Vejamos este exemplo de descrição no início da crônica $A$ nova profissão mais velha do mundo - quem não conhece a atmosfera outonal parisiense vai poder vivenciá-la:

\footnotetext{
O outono de Paris começou de repente, e tarde, este ano, com um vento glacial que despiu as árvores de suas últimas folhas douradas. Os terraços dos cafés fecharam ao meio-dia, a vida ficou turva e o verão radiante que se prolongara além da conta passou a ser uma fantasia de memória. Parecia que em poucas horas haviam se passado vários meses. $\mathrm{O}$ entardecer foi prematuro e lúgubre, mas ninguém o lamentou de verdade, pois esse tempo brumoso é o natural de Paris, o que mais a acompanha e que melhor lhe assenta (2006, p. 71).
}

Então se segue a narraçáo de um crime, uma prostituta das mais belas matando a outra, uma esplêndida loura, a tiros. E vem a revelação: "Nem a vítima nem o matador eram louras e belas, e sim, dois homens de fato e de direito, e ambos do Brasil" (2006, p. 71). Não resta dúvida de que o leitor tem aqui várias oportunidades de deslocamento e desvendamento de mundos: primeiro, a atmosfera outonal parisiense; depois, o impacto da transformação das mulheres em homens.

Isso é o efeito da literatura sobre o leitor e sobre esse efeito, o próprio escritor afirma que com a literatura, nada precisa ser explicado. Na crônica Poesia 
ao alcance das crianças, ele apresenta os desastres que a interpretação literária em sala de aula pode causar nos alunos e diz:

Devo ser um leitor muito ingênuo, porque nunca pensei que os romancistas quisessem dizer mais do que dizem. Quando Franz Kafka diz que Gregor Samsa despertou numa manhã, transformado num gigantesco inseto, não me parece que isso seja o símbolo de nada, e a única coisa que sempre me intrigou é que tipo de animal pode ter sido. Creio que de fato houve um tempo em que os tapetes voavam e havia gênios aprisionados nas garrafas. Creio que o asno de Balaão falou - como diz a Bíblia - e o lamentável é que não se gravou sua voz, e creio que Josué derrubou as muralhas de Jericó com o poder de suas trombetas e o lamentável é que ninguém transcreveu sua música demolidora. Creio, enfim, que o licenciado Vidrieras - de Cervantes - era na realidade de vidro, como ele acreditava em sua loucura, e creio para valer na alegre verdade de que Gargântua urinava em torrentes sobre as catedrais de Paris. Mais ainda: creio que outros prodígios semelhantes continuam a ocorrer e se não os vemos é porque somos impedidos pelo racionalismo obscurantista que nos inculcaram os maus professores de literatura (2006, p. 104-105).

Segundo Morin (1962), no processo do imaginário literário (Morin se refere também ao imaginário cinematográfico, mas o que nos interessa aqui é o poder da palavra desprovida de imagem visual):

Há um desdobramento do leitor (ou espectador) sobre os personagens, uma interiorização dos personagens dentro do leitor (ou espectador), simultâneas e complementares, segundo transferências incessantes e variáveis. Essas transferências psíquicas que asseguram a participação estética nos universos imaginários são ao mesmo tempo inframágicas (elas não chegam aos fenômenos propriamente mágicos) e supramágicas (elas correspondem a um estágio no qual a magia está superada). É sobre elas que se inserem as participaçóes e as considerações artísticas que concernem ao estilo da obra, sua originalidade, sua autenticidade, sua beleza, etc. (MORIN, 2007, p. 78).

Morin deixa claro que o processo do imaginário literário não está plenamente inserido no campo da magia, mas está diretamente ligado a ele, sendo inframágico e supramágico. Tratar-se-ia então de uma "degradação do mágico" devida ao processo civilizatório em que o homem se afasta gradualmente do seu pertencimento à natureza para afirmar-se cada vez mais pertencente ao universo da elaboração cultural racional e técnica. Na concepção moriniana, a palavra literária seria parte de um processo estético duplo de projeção/identificaçáo pelo autor criador da obra em um primeiro momento e pelo leitor fruidor da obra em um segundo momento: 
Entre a criação romanesca de um lado e a evocação dos espíritos por um feiticeiro ou um médium, de outro lado, os processos mentais são, até um certo grau, análogos. O romancista se projeta em seus heróis, como um espírito vodu que habita seus personagens, e inversamente, escreve sob seu ditado, como um médium possuído pelos espíritos (as personagens) que invocou. [...] Esse universo imaginário adquire vida para o leitor se este é, por sua vez, possuído e médium, isto é, se ele se projeta e se identifica com os personagens em situação, se ele vive neles e se eles vivem nele. (MORIN, 2007, p.78)

Ao que parece, a passagem do mágico para o supramágico - enquanto superação do mágico - no uso literário da palavra é muito mais um fenômeno de civilização e história correspondente à evolução ocidental do pensamento do que um fenômeno psicofísico. Com efeito, em termos psicofísicos, a literatura é um processo mediúnico de onde nasce uma forma ectoplasmática noológica projetada e objetivada na interação autor-leitor em um universo imaginário.

É o que faz com que Madame Bovary exista como uma referência comum a toda uma geração de leitores franceses, com que Capitu seja a mulher mais polêmica da história da literatura brasileira, Hamlet o filósofo dentro de cada homem etc. Podemos considerar que, quando os seres nascem do encontro entre a força da vontade criadora de um autor e a força da vontade imaginativa de um leitor, a evocação traz à vigência uma matéria físico-noológica na qual o componente noológico (psíquico-mental-ectoplasmático) é determinante e predomina. Para vigorarem, esses seres necessitam, em primeiro lugar, da palavra poética, mas também da repetição e da encenação que, na cultura ocidental se darão através das adaptaçóes, interpretaçóes, críticas e da intertextualidade.

Para além dos processos estéticos e imaginários, e supondo que nossa linguagem não seja apenas o resultado de um processo civilizatório, mas sim de uma relação estabelecida em vários níveis entre natureza e cultura, qual seria a propriedade evocatória da palavra literária e poética? Como se daria o poder criador evocatório da palavra em si mesma? Segundo os poetas, a palavra evoca aquilo que ela nomeia: o ser das coisas. Indo além da designação que fixa, paralisa e petrifica, a palavra literária recupera o ser das coisas. Um nome pode estar inadequado ou desgastado pelo uso, ele pode referir-se somente à aparência superficial das coisas. É preciso, então, encontrar a melhor configuração possível, o nome exato, aquele que nomeia o ser das coisas, aquele que terá, assim, o poder de trazer a coisa evocada à presença.

A palavra literária, assim encontrada, poderá fazer vigorar as coisas à presença dos leitores: um personagem, uma paisagem, um sentimento, uma atmosfera, uma ideia, um objeto. Quando a palavra traz as coisas à vigência, vemos, ouvimos, percebemos com os sentidos e reagimos a essa vigência. Por isso, podemos afirmar que a palavra literária não apenas evoca, mas convoca e provoca. Nisso ela é performática também no nível vertical da comunicação. 
O poder mágico evocatório da palavra no campo literário está presente em obras de todos os gêneros, sejam elas orais ou escritas: poesia, dramas, comédias, romances, contos, crônicas, textos jornalísticos literários - todos os gêneros se prazem no poder mágico da palavra evocatória; todos eles são suscetíveis de transportar autores e leitores a universos desconhecidos, de levá-los a conhecer seres desconhecidos, lugares imaginários, universos construídos no intangível limite entre a realidade e a ficção.

\section{Considerações finais}

Talvez possamos afirmar que haja, na América Latina, um tipo de jornalismo que só poderia ter nascido aqui, fruto de uma cultura híbrida, predominantemente oral, corporal, sensual e mágica. Aqui - onde também nasceu, na literatura do século XX, o realismo mágico - de fato, existe um jornalismo que é literário e mágico, sem deixar de ser, claro, realista. Talvez isso tenha uma explicação: a de que, em toda a América Latina, a realidade é outra. É mítica, poética e delirante, às vezes inacreditável e ficcional para as mentes formadas unicamente à ordem eurocentrada de percepção e narração do mundo.

Como, de fato, a Europa é o berço da moderna civilização da escrita, também berço do jornalismo, fica às vezes difícil entender como pode um jornalismo se formar segundo alguma outra escola que não a Europeia. Mas não é isso que acontece; o jornalismo latino-americano sempre olhou para a Europa e os Estados Unidos em busca de modelos e os encontrou; e os seguiu. Em matéria de jornalismo literário, os grandes expoentes foram sem dúvida os norte-americanos Gay Talese, Truman Capote e Tom Wolfe. Mas o que fizeram aqui - no Brasil, Clarice Lispector e Rubem Braga; na Argentina, Tomás Eloy Martinez e Ernesto Sábato; na Colômbia, Gabriel García Márquez, para citar apenas alguns - foi outra coisa. Aqui, na América Latina, os modelos se transformaram à medida de seu contato com uma realidade que não é - e não poderia ser - a mesma que a europeia ou a norte-americana.

Já se falou muito, ao menos aqui no Brasil, sobre a capacidade da cultura de engolir, processar e transformar os elementos culturais vindos de fora. Essa era a ideia do famoso conceito de Antropofagia Cultural, de Mário de Andrade e do Modernismo da Semana de 1922. Mas talvez não se tenha ainda tomado consciência da importância dessas transformaçóes e do poder criativo que as culturas da América Latina, em suas características híbridas, possuem. Talvez os próprios latino-americanos náo deem a devida importância à competência antropofágica de sua cultura e às possiblidades criativas e inovadoras que ela proporciona.

Certo é que Gabriel García Márquez sabia disso e publicou uma crônica onde mostrou como seu editor espanhol, de passagem por um dia em Cartagena, na Colômbia, teve que aprender, com uma rapidez estonteante e no mínimo arrebatadora, o que vem a ser o realismo mágico latino-americano 
para além da literatura. A crônica tem por título Um domingo de delírio e narra um domingo real numa cidade real de um país real da América Latina. Mas nesse continente, nessas culturas, as pessoas vivem e sentem, ouvem, se movem e consequentemente percebem e dizem o mundo de uma forma diferente do que acontece em outros lugares (na Espanha, por exemplo). Não é a língua que é diferente - é o que se coloca nas palavras. Talvez o que muda seja a própria realidade das palavras. Aqui, trechos da crônica que revelam essas diferenças e a sucessão de aparentes delírios, no entanto, tão reais:

[...] O delírio começou, no próprio aeroporto. Eu nunca observara, até que ele me fez notar, que as portas de embarque e desembarque são impossíveis de distinguir. De fato, há uma com um aviso que diz: 'Saída de passageiros' e por ela saem os que vão entrar nos aviōes. Há outra porta com outro aviso que diz a mesma coisa 'Saída de passageiros' e é por ali que saem os passageiros que chegam. [...] - Não se deve ligar para os letreiros - explicou-nos um agente de polícia de turismo - aqui todo mundo sabe por onde se entra e por onde se sai.

[...] Enquanto conversávamos chegou uma neta para nos contar que na noite anterior se desdobrara em duas: - Quando voltei do banheiro - me disse - me encontrei comigo mesma que ainda estava na cama.

Pouco depois, chegaram 3 irmãs e 2 irmãos, dos 16 que somos ao todo. Uma delas, que foi freira até há pouco, meteu-se numa discussão sobre religiôes comparadas com um irmão que é mórmon. Outro irmão mandara fazer uma mesa sob medida, mas quando voltou a medi-la em casa, ela estava menor do que na carpintaria: - É que no Caribe, não há dois metros iguais, disse.

[...] Outra irmã tocava ao piano a serenata do quarteto número cinco de Haydn. Ponderei-lhe que tocava com tanta rapidez que parecia uma mazurca. - É que só toco piano quando estou acelerada - me disse Toco para tentar me acalmar, mas a única coisa que consigo é acelerar também o piano.

Estávamos assim, quando bateu à porta uma irmã de minha mãe, a tia Elvira, de 84 anos, a quem não víamos havia 15 anos. Vinha de Riohacha, num táxi expresso, e envolvera a cabeça com um velho pano preto para se proteger do sol. Entrou feliz com os braços abertos e disse para que todos ouvissem: - Venho me despedir, porque já estou quase morrendo (2006, p. 127-130).

Esta crônica parece mentira aos olhos de um leitor europeu ou de qualquer leitor blasé; parece uma série de acontecimentos plausíveis reunidos para efeito retórico. Mas foram vividos em um dia só e foram "a maior lição de realismo mágico” recebida pelo editor espanhol de García Márquez, segundo as próprias palavras do autor. Não deve ter sido fácil de admitir. 
Nós, no Brasil, também compartilhamos esse tipo de realidade e sabemos que nosso realismo cotidiano é diferente do realismo europeu. Por isso, o jornalismo, por mais que se esforcem os aprendizes jornalistas formados segundo as clássicas escolas da Europa e dos Estados Unidos, também há de não ser o mesmo. Aqui, a realidade é mais literária, mais mítica, mais mágica; o olhar sobre o mundo é mais poético. Por isso, no Brasil, como na Argentina, no México, na Colômbia e em toda a América Latina, as condiçóes para que floresça um tipo específico de jornalismo literário parecem propícias.

\section{Referências Bibliográficas}

CASTRO, Gustavo de. Jornalismo literário. Brasília: Casa das Musas, 2010. GARCÍA MÁRQUEZ, Gabriel. Crônicas 1961-1984 - Obra jornalística 5. Rio de Janeiro: Record, 2006.

MORAES, Regis de. As razóes do mito. Campinas: Papirus, 1988.

MORIN, Edgar. Cultura de massas no século XX - O espírito do tempo. Vol.1 Neurose. Rio de Janeiro: Forense Universitária, 2007. 